\title{
Effects of Shear Mechanisms on Impact Behavior of Reinforced Concrete Beams
}

\author{
by Selcuk Saatci and Frank J. Vecchio
}

\begin{abstract}
A well-instrumented experimental program was undertaken to contribute to our understanding of the effects of shear mechanisms on the behavior of reinforced concrete $(R C)$ structures under impact loads and to provide data for verification of methods developed for the impact analysis of such structures. Eight RC beam specimens, four pairs, were tested under free-falling drop-weights, impacting the specimens at the midspan. All specimens had identical longitudinal reinforcement, but varying shear reinforcement ratios, intended to investigate the effects of shear capacity on the impact behavior. A total of 20 impact tests were conducted, including multiple tests on each specimen. The test program was successful in providing a substantial amount of high-quality impact test data. The test results showed that the shear characteristics of the specimens played an important role in their overall behavior. All specimens, regardless of their shear capacity, developed severe diagonal shear cracks, forming a shear-plug under the impact point.
\end{abstract}

Keywords: dynamic equilibrium; energy absorption; impact capacity; impact test; reinforced concrete; shear.

\section{INTRODUCTION}

The analysis and design of reinforced concrete (RC) structures for resistance against extreme loads (such as earthquake, blast, and impact) have been studied by many researchers and designers. Moreover, as a result of recently elevated terror threat levels in the world, the demand for impact-resistant design of buildings has increased. Consequently, numerous experimental, analytical, and numerical studies have been conducted toward understanding and developing methodologies predicting the behavior of RC structures under impact loads.

Experimental studies carried out in this area have revealed that shear mechanisms play an important role in the overall impact behavior of RC structures. Severe shear cracks and deformations, such as shear plugs at the impact location, were observed in the majority of the experimental impact studies. For example, studies carried out by Feldman et al., Kishi et al., ${ }^{2,3} \mathrm{Ho},{ }^{4}$ and May et al. ${ }^{5}$ reported severe diagonal shear cracks even with statically flexural-critical RC beams tested under impact loads applied at the midspan.

Most experimental studies, however, concentrated their efforts on developing an empirical impact-resistant design method, and typically little effort was spent toward understanding the shear and cracking mechanisms involved. Moreover, the majority of the impact experiments reported in the literature were qualitative in nature. Due to the complexities involved, little information was collected and reported for such experiments.

This paper presents the details of a well-instrumented experimental program, aimed at investigating the role of shear mechanisms on the impact behavior of RC members, as well as providing detailed impact test data that will assist the development and verification of accurate analytical and numerical methods for predicting the impact response. The test program was devised to observe the effects of the static shear capacity of the RC beams on the impact behavior, involving eight RC beams (four pairs), with varying static shear capacities, tested under free-falling impact weights. This paper documents the details of the test program, including specimen properties, test setup, instrumentation, and test procedures. Test results and major observations are also presented and discussed. The study presented in this paper constitutes the experimental phase of a wider study that also includes numerical and analytical investigations, which will be presented and discussed in papers to follow.

\section{RESEARCH SIGNIFICANCE}

Demand for impact-resistant RC structures is increasing and, thus, many recent experimental studies have been carried out aimed at developing analysis and design methods for such structures. In many of these studies, severe shear mechanisms, such as shear plugs, were observed. Little effort, however, was spent to explain their role in the overall impact behavior of the structure.

This paper presents an experimental program with two major objectives: 1) understanding the effect of shear mechanisms in the overall impact behavior; and 2) supplying the literature with detailed impact test data that can assist further analytical and numerical studies in the area.

\section{EXPERIMENTAL PROCEDURE}

The experimental program, carried out at the University of Toronto Structural Laboratories, consisted of two phases: impact tests and static tests. The impact tests involved eight $\mathrm{RC}$ beams, grouped in four pairs. Each pair consisted of identical specimens, cast at the same time and using the same concrete batch, to ensure identical concrete properties. These specimens are denoted with "SS," followed by the specimen type number and the letters "a" and "b" to distinguish the identical specimens. Four additional specimens were cast to determine the static behavior of the specimens tested under impact loading. Each static specimen had an identical reinforcement layout as its corresponding impact specimen; these beams were denoted with "MS," followed by the specimen type number. Impact and static specimens having the same specimen type number had the identical reinforcement layout (for example, SS2a and SS2b had an identical reinforcement layout with MS2). All static specimens were cast

ACI Structural Journal, V. 106, No. 1, January-February 2009.

MS No. S-2007-226 received June 13, 2007, and reviewed under Institute publication policies. Copyright (C) 2009, American Concrete Institute. All rights reserved, including the making of copies unless permission is obtained from the copyright proprietors. Pertinent discussion including author's closure, if any, will be published in the November-December 2009 ACI Structural Journal if the discussion is received by July 1,2009. 
Selcuk Saatci is an Assistant Professor in the Civil Engineering Department, Izmir Institute of Technology, Izmir. Turkey. He received his BS and MS from the Middle East Technical University, Ankara, Turkey, and his PhD from the University of Toronto, Toronto, ON, Canada. His research interests include the impact behavior and nonlinear finite element analysis of reinforced concrete structures.

Frank J. Vecchio, FACI, is a Professor of civil engineering at the University of Toronto. He is a member of Joint ACI-ASCE Committee 441, Reinforced Concrete Columns, and 447, Finite Element Analysis of Reinforced Concrete Structures. He received the ACI Chester Paul Siess Award for Excellence in Structural Research in 1998 and the ACI Structural Engineering Award in 1999.

at the same time using the same concrete batch; therefore, all had an identical concrete strength, close to the average concrete strength attained in the impact specimens.

All the specimens were $250 \mathrm{~mm}$ (9.8 in.) in width, $410 \mathrm{~mm}$ (16.1 in.) in height, and $4880 \mathrm{~mm}$ (192 in.) in length. The specimens were tested under simply supported conditions with a shear span of $1500 \mathrm{~mm}$ (59 in.), leaving a $940 \mathrm{~mm}$ (37 in.) overhang at each end. The overhangs were intended both to amplify the inertia effects on the response and to obtain fully developed longitudinal bars at the supports. The specimens were supported at the bottom with heavy steel pedestals fixed to the strong floor. The test setup at the supports was devised to prevent uplift of the specimen without creating restraint moments at the supports during the vibrations induced by impact loads (refer to Fig. 1). All specimens were doubly reinforced with the longitudinal reinforcement bars placed symmetrically along the height of the specimens and spanning the entire length of the specimen. No. 30 bars (CSA Standard G30.18), with a $700 \mathrm{~mm}^{2}\left(1.09 \mathrm{in}^{2}\right.$ )

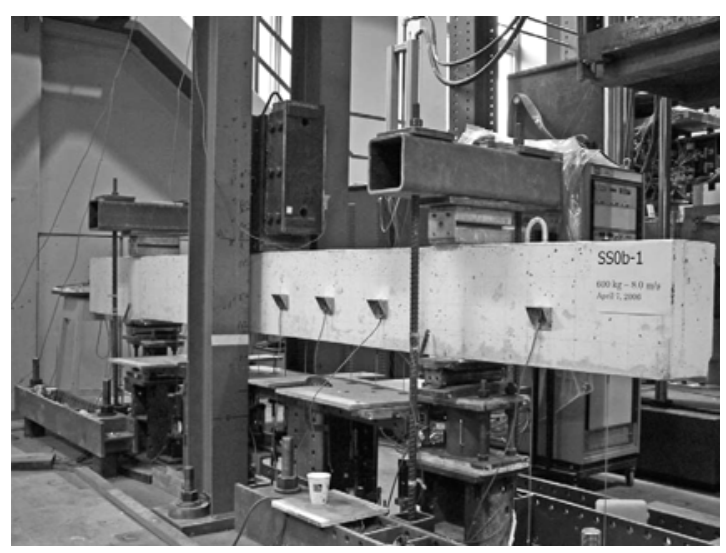

Fig. 1-Test setup.
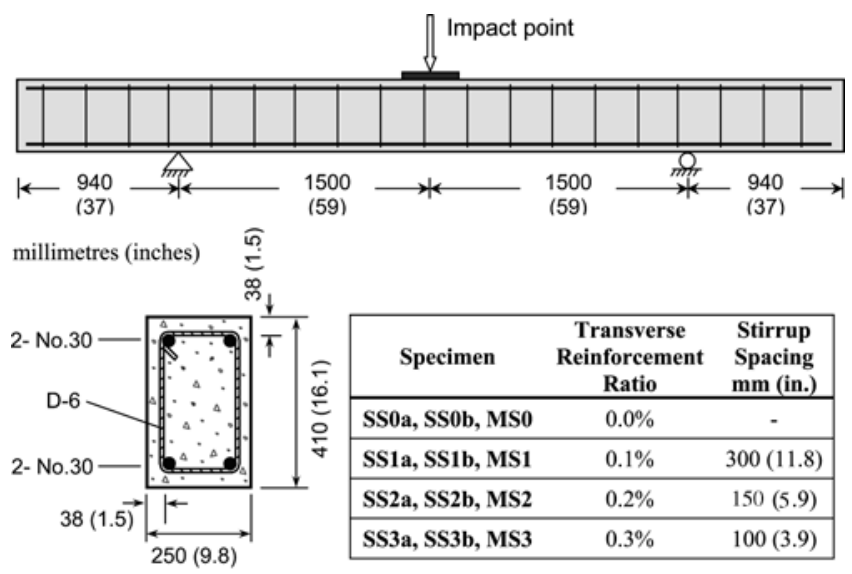

Typical cross section

Fig. 2-Specimen properties. cross-sectional area and a $29.9 \mathrm{~mm}$ (1.18 in.) nominal diameter, were used as longitudinal reinforcement. A $38 \mathrm{~mm}$ (1.5 in.) clear cover was provided between the top and the bottom beam surfaces and the bars. The transverse reinforcement ratios were varied as $0.0,0.1,0.2$, and $0.4 \%$ between different types of specimens. Closed stirrups were used, fabricated from U.S. Standard D-6 deformed wire with a $38.71 \mathrm{~mm}^{2}\left(0.06 \mathrm{in}^{2}\right)$ cross-sectional area and a $7.01 \mathrm{~mm}$ (0.276 in.) diameter. Details of the specimens are presented in Fig. 2 and the material properties of the specimens are summarized in Table 1. Figure 3 presents the stress-strain responses of the concrete and steel bars, obtained from standard cylinder and coupon tests, respectively.

\section{Table 1-Material properties of test specimens}

\begin{tabular}{c|c|c|c}
\hline Specimen & $\begin{array}{c}\text { Peak compressive } \\
\text { stress } \boldsymbol{f}_{\boldsymbol{c}}{ }^{\prime}, \text { MPa (ksi) }\end{array}$ & $\begin{array}{c}\text { Strain at peak } \\
\text { compressive stress } \varepsilon_{\mathbf{0}}\end{array}$ & $\begin{array}{c}\text { Modulus of rupture } \\
\boldsymbol{f}_{\boldsymbol{r} \boldsymbol{p}}, \text { MPa (ksi) }\end{array}$ \\
\hline $\begin{array}{c}\text { SS3a, } \\
\text { SS3b }\end{array}$ & $46.7(6.77)$ & $2.51 \times 10^{-3}$ & $5.8(0.84)$ \\
\hline $\begin{array}{c}\text { SS2a, } \\
\text { SS2b }\end{array}$ & $47.0(6.82)$ & $2.42 \times 10^{-3}$ & $6.2(0.90)$ \\
\hline $\begin{array}{c}\text { SS1a, } \\
\text { SS1b }\end{array}$ & $44.7(6.48)$ & $2.36 \times 10^{-3}$ & $5.6(0.81)$ \\
\hline $\begin{array}{c}\text { SS0a, } \\
\text { SS0b }\end{array}$ & $50.1(7.27)$ & $2.32 \times 10^{-3}$ & $5.9(0.86)$ \\
\hline $\begin{array}{l}\text { MS0,MS1, } \\
\text { MS2, MS3 }\end{array}$ & $55.2(8.00)$ & $2.35 \times 10^{-3}$ & Not measured \\
\hline $\begin{array}{c}\text { Steel bar } \\
\text { No. 30 }\end{array}$ & $\begin{array}{c}\text { Yield stress } \boldsymbol{f}_{\boldsymbol{y}}, \\
\text { MPa (ksi) }\end{array}$ & Yield strain $\boldsymbol{\varepsilon}_{\boldsymbol{y}}$ & $\begin{array}{c}\text { Ultimate strength } \\
\boldsymbol{f}_{\boldsymbol{u}}, \text { MPa (ksi) }\end{array}$ \\
\hline D-6 & $605(87.3)$ & $2.38 \times 10^{-3}$ & $630(91.4)$ \\
\hline
\end{tabular}

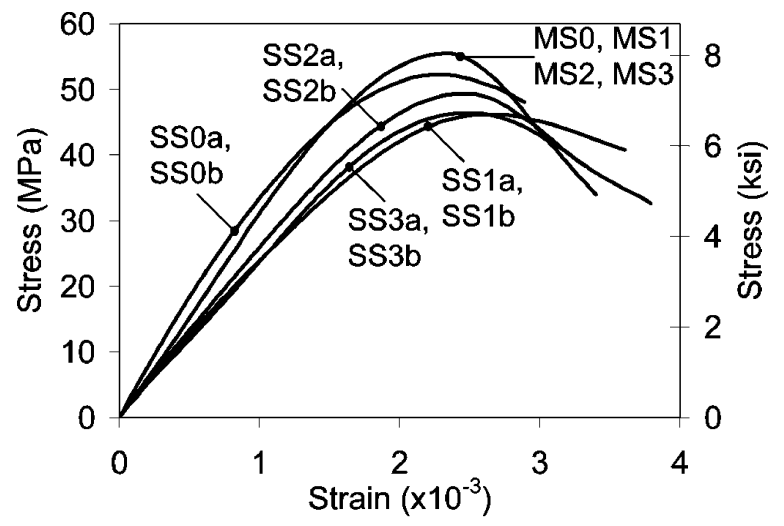

(a) Concrete cylinder responses

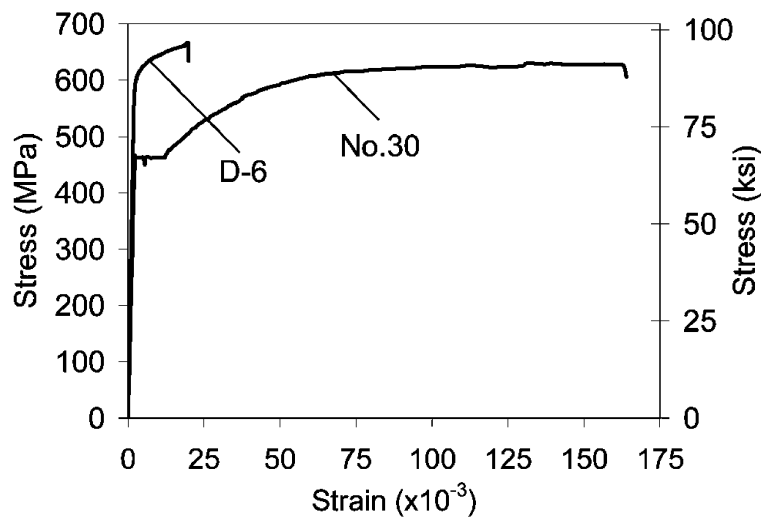

(b) Steel bar coupon responses

Fig. 3-Stress-strain response for concrete and steel bars. 
The impact specimens in this test program were well instrumented. Seven accelerometers were used for each test-five were mounted on the specimen to measure the accelerations during the impact-induced vibrations and two were mounted on the drop-weight to characterize the impact force. Fifteen potentiometers were attached along the bottom surface of the specimen, at regular intervals, to measure vertical displacements (refer to Fig. 4). All longitudinal bars were fitted with electrical-resistance strain gauges, applied at three different locations. Three stirrups in each beam were also fitted with the same type of strain gauges. Two load cells were used at the supports to measure the reaction forces. The data collected were captured at a $2.4 \mathrm{kHz}$ sampling rate by a digital data acquisition system.

Two different drop-weights were used for the impact testing: a lighter weight of $211 \mathrm{~kg}(465 \mathrm{lb})$ and a heavier weight of $600 \mathrm{~kg}(1323 \mathrm{lb})$. The drop-weights were manufactured with $305 \mathrm{~mm}$ (12 in.) square hollow structural steel (HSS) sections filled with concrete and steel plates, and their weights were arbitrarily chosen to induce different levels of damage to the specimens with each impact. Impact loads were applied via the free-fall of the drop-weights impacting the specimens at the midspan. The contact surfaces of the dropweights were flat, and a $50 \mathrm{~mm}$ ( 2 in.) thick, $305 \mathrm{~mm}$ (12 in.) square steel plate was placed on top of the beam at impact point to obtain a well-distributed impact force.

The weights were dropped from a clear height of $3.26 \mathrm{~m}$ (128.3 in.) above the specimen, resulting in an $8.0 \mathrm{~m} / \mathrm{second}$ (26.25 ft/second) calculated impact velocity. All specimens with the exception of SSOb were subjected to multiple impacts. With the a-series specimens, the beams were first tested once with the smaller drop-weight, followed by two tests with the larger one. For b-series specimens, the order was reversed; they were tested twice with the larger dropweight, and then one last time with the smaller drop-weight. The varied protocol used in delivering the impact energy was intended to observe the effect of previous damage on the resistance characteristics of the specimens. Using this procedure, the total impact energy imparted to the specimens was kept constant between twin specimens, except for those that failed prior to the second or third impact (SSOa and SS1b were tested twice, and SSOb was tested only once).

\section{Table 2-Static capacities of test specimens}

\begin{tabular}{c|c|c|c}
\hline Specimen & $\begin{array}{c}\text { Maximum static reaction } \\
\text { force, }{ }^{*} \mathrm{kN}(\mathrm{kips})\end{array}$ & $\begin{array}{c}\text { Static energy } \\
\text { dissipation capacity, } \\
\text { kJ (ft-lbf) }\end{array}$ & $\begin{array}{c}\text { Failure } \\
\text { mode }\end{array}$ \\
\hline MS3 (SS3a, SS3b) & $199(45)$ & $27.8(20,500)$ & Flexural \\
\hline MS2 (SS2a, SS2b) & $193(43)$ & $28.0(20,700)$ & Flexural \\
\hline MS1 (SS1a, SS1b) & $149(33)$ & $3.0(2200)$ & Shear \\
\hline MS0 (SS0a, SS0b) & $98(22)$ & $0.9(660)$ & Shear \\
\hline
\end{tabular}

* Maximum applied midspan load divided by 2 .

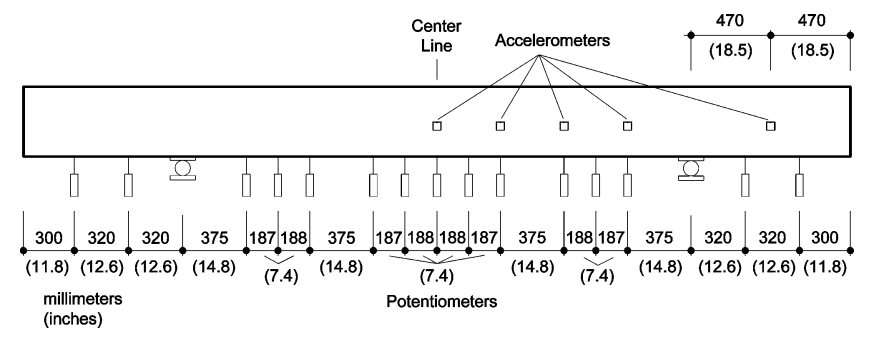

Fig. 4-Accelerometer and potentiometer locations.
After the completion of the impact test program, the corresponding static specimens were tested under monotonically increasing static loads to determine their static capacity and behavior. These specimens were loaded at the midspan, with support conditions identical to those used with the impact tests.

\section{EXPERIMENTAL RESULTS AND DISCUSSIONS}

\section{Static test results}

The midspan load-deflection responses obtained from static tests are presented in Fig. 5. Specimens MS0 and MS1 failed in a shear-critical mode with the formation of a principal diagonal shear crack, whereas MS2 and MS3 exhibited a ductile flexural response. Table 2 presents the maximum reaction forces measured during the static tests for each specimen. Static energy dissipation capacities, based on the area under static midspan displacement-total load curve, are also calculated and presented in the same table.

\section{Impact test results}

As mentioned previously, the data collected by the sensors were recorded using a high-speed digital data acquisition system. The midspan displacements and support reactions (measured at one support) are presented in Fig. 6 and 7, for the first impacts on a- and b-series specimens, respectively (note that the results for SSOb-1 are omitted because the data were not reliable due to extensive damage). In addition, after each test, the cracks that developed were marked, and their widths were measured. Figures 8 and 9 present the sketches of the crack maps of the specimens at their final stage (after the multiple impact tests). The complete test data obtained from the sensors are available in digital format at the University of Toronto-VecTor Analysis Group Web site. ${ }^{6}$ Detailed reports on the individual tests and complete crack maps can be found elsewhere. $^{7}$

The following sections summarize and discuss the main observations made during the impact tests. In the notation used to denote the impact tests, the number following the specimen name indicates the sequence of the particular test performed on that specimen.

\section{Crack patterns}

As seen in Fig. 5, the static tests revealed that SS3 and SS2 (identical to MS3 and MS2, respectively) exhibited a ductile flexure-critical behavior, whereas under static loading, SS1

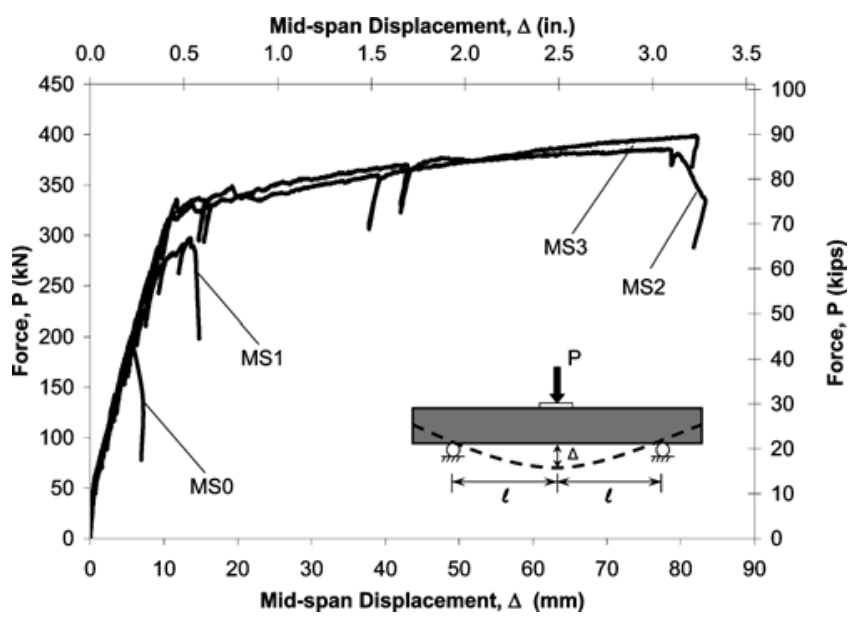

Fig. 5-Static response of test specimens. 
and SS0 (identical to MS1 and MS0, respectively) were shear-critical. During the impact testing, however, regardless of their projected static behavior, all specimens developed severe diagonal cracks, originating at the impact point and propagating downward with an angle of approximately 45 degrees, forming shear-plugs. In addition, several diagonal cracks parallel to the major shear-plug cracks also developed, along with some vertical flexural cracks at the midspan and at the supports. Flexural cracks usually propagated vertically through the height of the beams. The vertical cracks at the midspan started from the bottom surface, whereas the cracks close to the supports started from the top surface. Several other short vertical cracks, starting from the top of the specimens, were also observed in most of the specimens due to negative bending moments at the initial stages of the impact response. Mechanisms involved in the formation of these vertical cracks are discussed in the following section.

The crack patterns and failure modes varied between specimens, depending on their static capacities. For example, in the flexure-critical specimens, SS2 and SS3, vertical flexural cracks at the midspan were more visible and wider, whereas they were shorter and narrower in shearcritical members, SS1 and SS0. In SS2 and SS3, subsequent
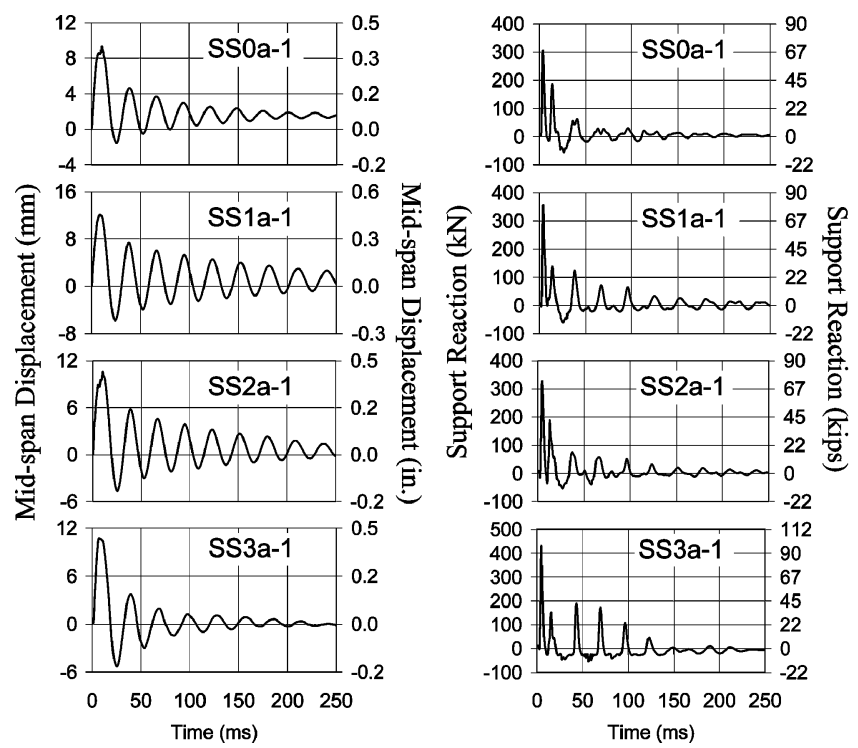

Fig. 6-Midspan displacements and support reactions for a-series specimens (first impact).
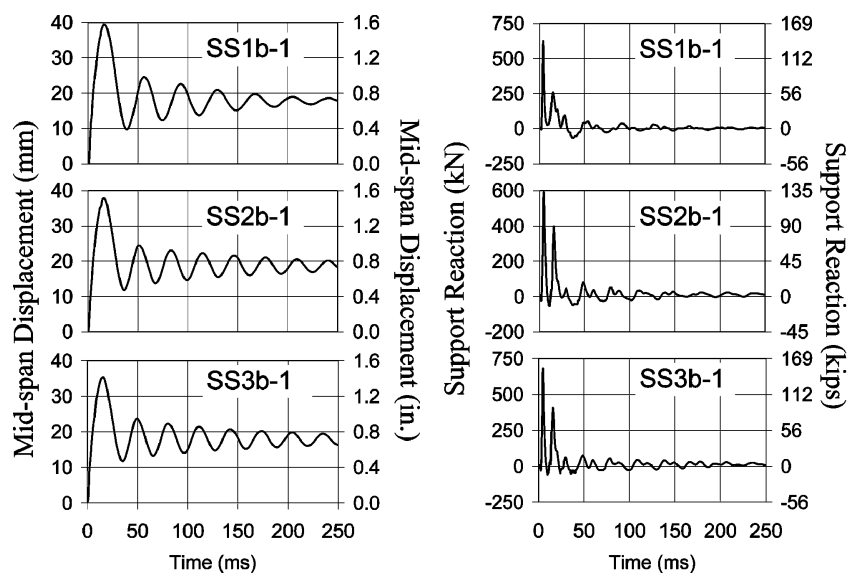

Fig. 7-Midspan displacements and support reactions for $b$-series specimens (first impact). impacts on the damaged specimens did not change the widths of the cracks located beyond the major diagonal cracks forming the shear-plug; increasing deformations were mostly accommodated by the widening of shear cracks forming the shear-plug. In SS1 and SS0, however, another diagonal crack developed alongside the shear-plug, which started from the supports, propagating at an angle of approximately 45 degrees upward, and became horizontal close to the top before reaching the impact zone (refer to Fig. 10). These cracks were quite similar in nature to the typical shear cracks that result in the failure of shear-critical beams under static loads, and they became wider with subsequent impacts, causing the failure of the specimens in SS1a-3, SS0a-2, SS1b-2, and SSOb-1.

Observations made from the development of crack profiles and crack widths revealed that the failure modes were deter-

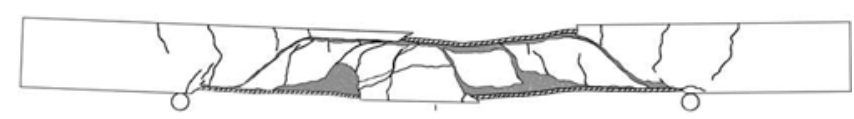

(a) SS0a

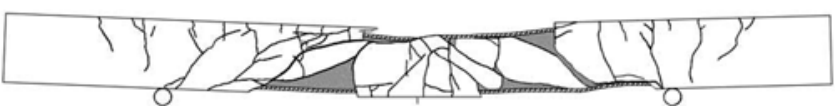

(b) SS1a

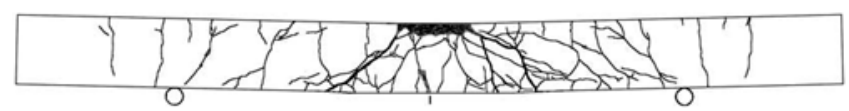

(c) $\mathbf{S S 2 a}$

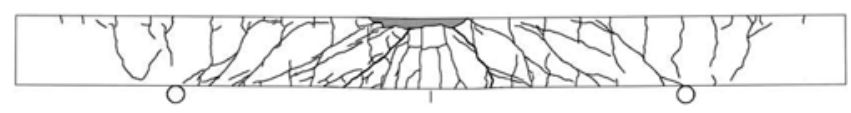

(d) SS3a

Fig. 8-Final crack profiles for a-series specimens.

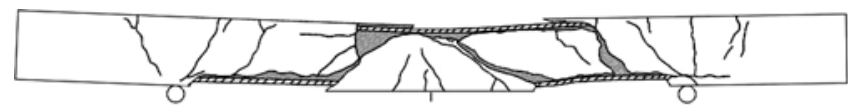

(a) $\mathbf{S S O b}$

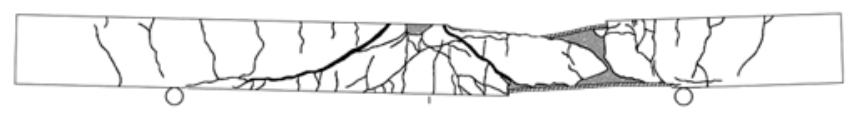

(b) SS1b

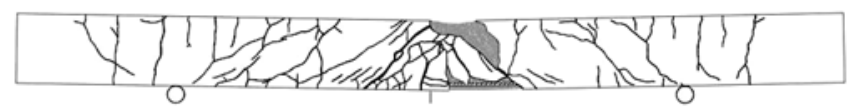

(c) $\mathbf{S S 2 b}$

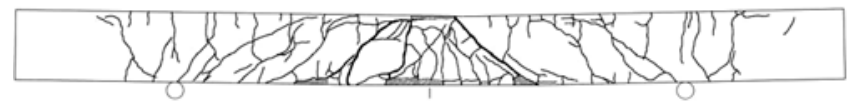

(d) $\mathbf{S S 3} \mathbf{b}$

Fig. 9-Final crack profiles for b-series specimens.

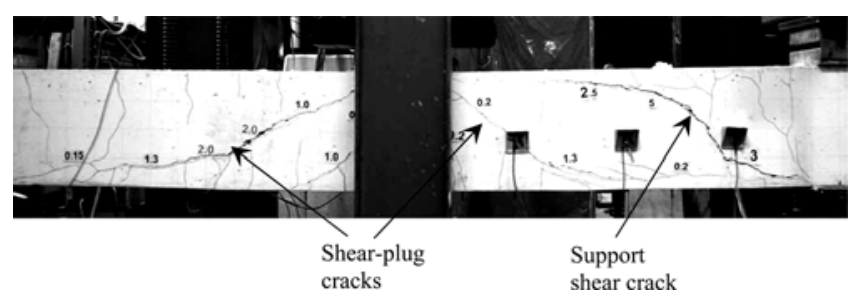

Fig. 10-Typical cracks in a shear-critical specimen (SS1b-1). 
mined mainly by the static behavior of the specimens. In the flexure-critical specimens, shear-plugs developed faster than did the support shear cracks. Their capacities were higher, comparing the damage these beams sustained relative to the damage suffered by the shear-critical specimens, after three impacts. Although they developed pronounced shear-plugs as well, failure of the shear-critical specimens was not entirely a result of the shear-plugs, but also involved shear failure at the supports. In other words, the shear strengths of flexure-critical specimens were sufficient to carry the shear forces beyond the shear-plug to the supports. Subsequent impacts pushed the shear-plug down further without creating significant damage in other regions of the specimen. This was not the case, however, for shear-critical members. These specimens did not have sufficient strength to transmit the shear forces to the supports. Consequently, the shear forces beyond the shear-plug caused extensive damage between the shear-plug and the supports, ultimately failing the beams in this region. In any case, none of the specimens exhibited significant flexural deformations. The flexure-critical beams developed some wide vertical cracks, but their widths were always less than the width of the diagonal shear cracks. Because the deformations caused by the shear-plugs dominated the displacement profile, the shearcritical specimens developed much narrower flexural cracks.

\section{Distribution of forces and dynamic equilibrium}

In simple terms, when a drop-weight impacts a beam specimen, the resulting impact force is resisted by the stiffness of the beam, while the beam accelerates in the direction of the impact force. The acceleration of the beam creates inertia forces, equal in magnitude to the mass times acceleration integrated over the volume. If the direction of

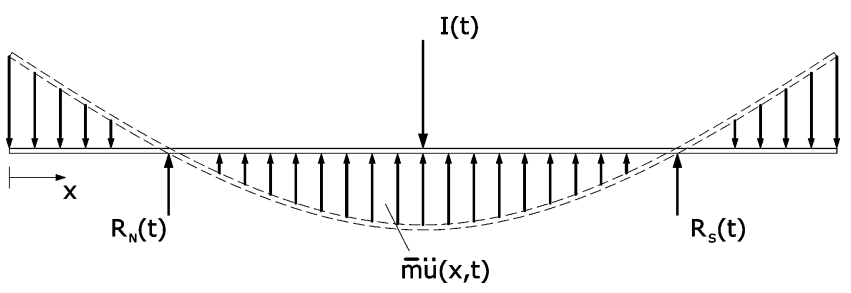

Fig. 11-Dynamic free body diagram for the test specimens.

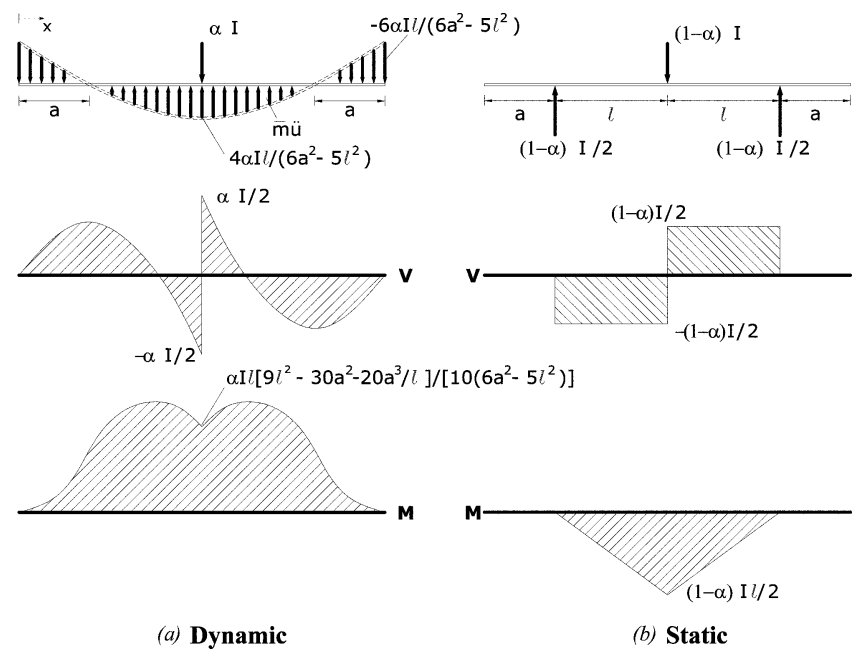

Fig. 12-Distribution of forces and resulting moment and shear diagrams. these inertia forces is taken as opposite to the direction of the accelerations, then a state of force equilibrium can be established for that point in time. Ignoring the damping forces, a free body diagram for this state of dynamic equilibrium can be derived for the test specimens as shown in Fig. 11, where $I(t)$ is the impact force, $\bar{m}$ is the mass per unit length, $\ddot{u}(x, t)$ is the acceleration of the specimen, and $R_{N}(t)$ and $R_{S}(t)$ are the support reaction forces at the north and south supports, respectively. According to this free body diagram, the vertical force equilibrium of the specimen at any time $t$ can be expressed as follows

$$
\int_{0}^{L} \bar{m} \ddot{u}(x, t) d x+R_{N}(t)+R_{S}(t)-I(t)=0
$$

where $L$ is the total length of the specimen. In this test program, all quantities in Eq. (1) were measured during the tests; accelerations on the specimen were measured by accelerometers attached to the south half of the specimen at five different locations, the support reactions $R_{N}(t)$ and $R_{S}(t)$ were obtained from the load cell readings, and the impact forces $I(t)$ were calculated as the product of the accelerations of the drop-weight multiplied by its mass. This provided an opportunity to verify the test data for dynamic equilibrium and examine the corresponding behavior of the specimens.

An investigation, similar to the one described by $\mathrm{CEB},{ }^{8}$ can reveal the distribution of forces along the specimen. As stated in Eq. (1), the impact force is resisted by a combination of inertia and reaction forces. The distribution of these forces, and the resulting shear and moment distributions, can be determined using the basic principles of static equilibrium, as shown in Fig. 12, where $a$ is the length of the overhang, $l$ is the shear span, $I$ is the impact force, $\alpha$ is the ratio of the inertia forces to the total impact force, and where the inertia force distribution is assumed proportional to the elastic displaced shape of the specimen loaded at the midspan. The total reaction force at the supports can be found as follows

$$
R=(1-\alpha) \frac{I}{2}
$$

which can be matched against the test results to find the value of $\alpha$. In SS3a-1, for example, the peak impact force was $1421 \mathrm{kN}$ (319.5 kips) and the total support reaction at the same point in time was $13.1 \mathrm{kN}$ (2.9 kips), giving $\alpha=$ 0.98. The same calculations done for other tests also gave $\alpha$ values close to 1.0 for the first peak, meaning that almost all the impact force was resisted by the inertia forces at the first instant, before it was transmitted to the supports. This can be seen more clearly when the resisting forces are broken down to their components, as done in Fig. 13 for SS3a-1. This phenomenon also explains the formation of the shear-plug. As seen in the moment diagrams in Fig. 12, the midspan moment for the case of $\alpha=1.0$ is much smaller than it is for the static case of $\alpha=0.0$. If values of $a=0.94 \mathrm{~m} \mathrm{(37} \mathrm{in.)} \mathrm{and}$ $l=1.5 \mathrm{~m}$ (59.06 in.) are substituted, it can be found that the maximum moment for $\alpha=1.0$ is $0.437 \mathrm{I}$, whereas for $\alpha=0.0$, it is $0.75 \mathrm{I}$. The midspan shear force, however, is independent of $\alpha$, and always equal to $I / 2$. Therefore, in the initial stages of the response, the specimen experiences the same shear force but significantly smaller moments than it would under static loading, thus becoming shear-critical, forming the diagonal shear cracks and the subsequent shear-plug. 
Another consequence of $\alpha$ being close to 1.0 in the initial stages of the response is the vertical cracks observed along the specimen. As seen in the moment diagram presented in Fig. $12, \alpha \approx 1.0$ creates negative moments along the entire length of the specimen. These negative moments resulted in vertical cracks starting from the top and propagating downward (refer to Fig. 14(a)). Typically, these cracks were spaced closer on the specimens with higher stirrup ratios compared with the specimens with larger stirrup spacings. They were characterized by narrow crack widths (typically approximately $0.10 \mathrm{~mm}[0.0040 \mathrm{in}]$.$) , because they formed in the very early$ stages of the response and closed quickly after the negative moments diminished, that is, as the $\alpha$-value approached zero. Vertical cracks developed within the overhanging regions as well; however, they had an inclination toward the supports as they propagated downward, due to the high shear forces at the supports along with negative moments when $\alpha \approx 1.0$ (refer to Fig. 14(b)).

\section{Displaced shapes}

Displacement data represent the easiest and most direct measure of comparison to the results of any numerical or analytical method, and they can provide important information regarding the validity of the methodology. Moreover, some analytical methods begin with an assumed displaced shape, such as those employing single-degree-of-freedom (SDOF) analysis, to derive the inertia and other forces acting on a specimen; a well-predicted displaced shape is critical to the accuracy of such methods. As mentioned previously, closely spaced displacement sensors were connected to the test specimens along the entire length of their bottom face. Assuming zero displacement at the supports, the displaced shape of the specimens could be determined for each sampling point in time. These shapes, obtained up to the first peak of the vibrations, are presented in Fig. 15 for the first impacts on b-series specimens. Note that, in all figures, the displaced shapes are given in $2.50 \mathrm{~ms}$ intervals as the specimens deflected downward. Recorded data points were connected by smoothened lines.

The failure modes and the formation of the shear-plug can be observed in the displaced shapes to some extent. Instead of bending with the shape of a beam statically loaded at the midspan, the drop-weight punched out the middle segment of the specimens forming a shear-plug, evidenced in the very similar measurements of the middle three displacements in all tests. This behavior was less apparent in the specimen

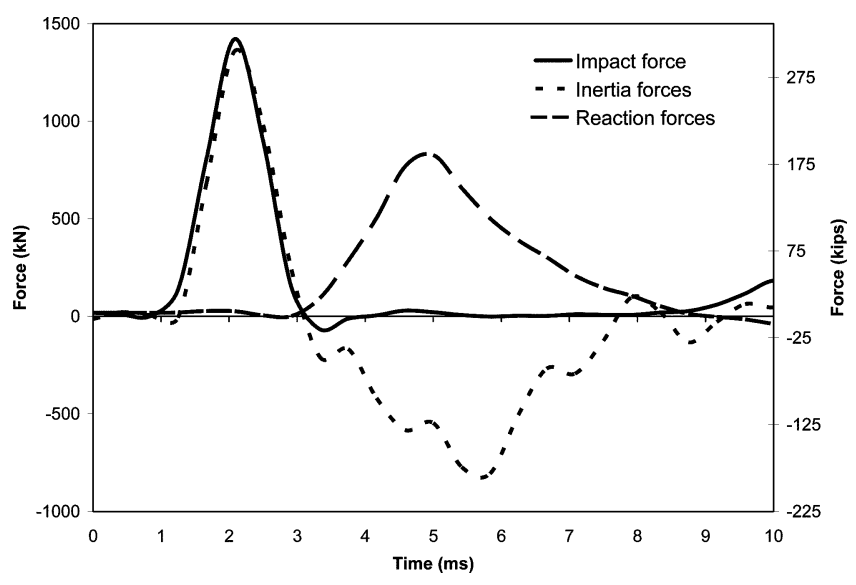

Fig. 13-Breakdown of resisting forces, SS3a-1. with the highest stirrup ratio, SS3b, because the stirrups significantly reinforced the specimen against shear, allowing the bending of the middle segment to a certain degree. In $\mathrm{SS} 1 \mathrm{~b}$, on the other hand, there was notably less bending in the middle segment, evidenced by the comparable displacements recorded by the middle five sensors. SSOb had no stirrups; hence, the middle segment punched through with almost no visible bending deformations. The failure of the specimen at both supports can be observed clearly in the displaced shape. (Note that the data points are connected with a continuous line in the figures, ignoring the discontinuity due to crack openings.)

It is useful to examine whether the specimens deflected in a manner similar to their static deflected shapes because some practical analytical methods that employ the SDOF system assumption usually choose the static elastic displaced shape of the specimen as the unit displaced shape. In this case, the displaced shape of an elastic beam with a point load at the midspan would be the logical choice for the unit displaced shape, as given in Eq. (3).

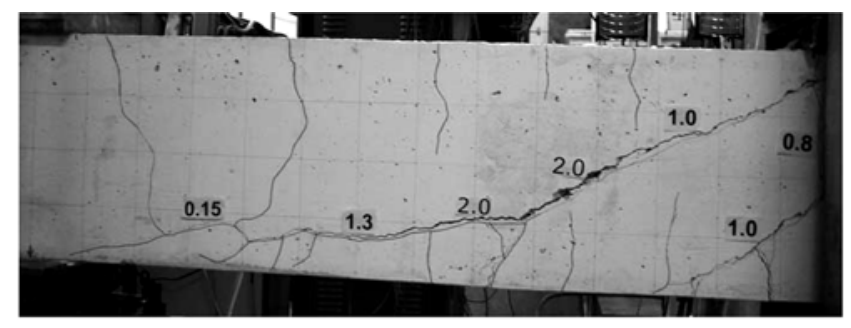

(a) Vertical cracks due to negative moments, SS1b-1

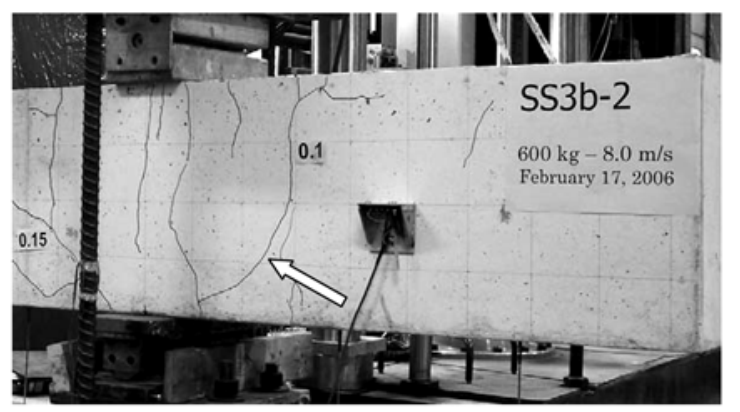

(b) Inclination of a vertical crack at the overhanging part, SS3b-2

Fig. 14-Effects of dynamic force distribution.
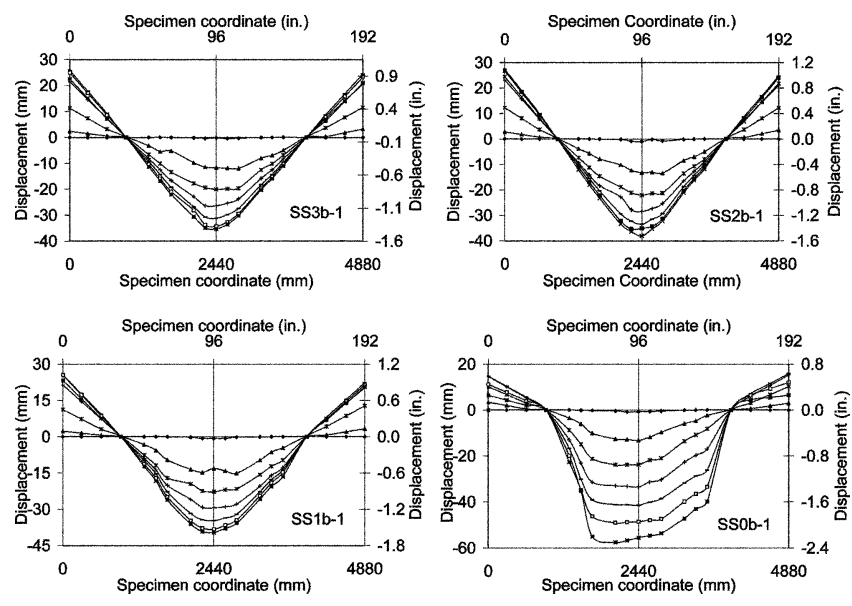

Fig. 15-Displaced shapes (2.50 ms intervals). 


$$
u(x)=\frac{P l^{2}}{4 E I}(a-x) \text { for } x \leq a
$$

$u(x)=\frac{P}{12 E I}(x-a)^{3}-\frac{P l^{2}}{4 E I}(x-a)$ for $a<x \leq(a+l)$

where $u(x)$ is the displacement, $P$ is the point load at the midspan, $E$ is the elastic modulus, $I$ is the moment of inertia, and $x$ is the coordinate from the left end of the beam. Note that the displaced shape is symmetrical around the midspan (that is, $x=a+l$ ). The elastic displaced shapes can be fit into the midspan displacement and compared with the displacement profile measured at the time of the peak midspan displacement, as presented in Fig. 16(a). Although in Fig. 16(a) it might appear that the segment between the supports actually does correspond well to the elastic displaced shape for SS3b-1 and SS1b-1, some discrepancies exist between the elastic and measured shapes due to the shear-plug formation and the resulting discontinuities in the displaced profile. These discrepancies would become more visible if the elastic shape was fit into the slope of the same displacement profile at the supports instead of the midspan displacement, as shown in Fig. 16(b). In this figure, it can be seen that the measured displaced shape around the midspan actually deviates
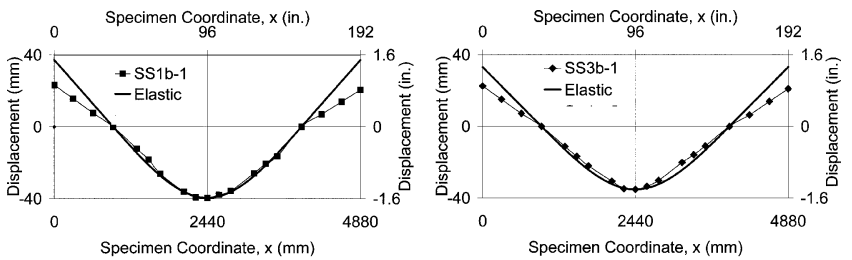

(a) Elastic shape fit into the measured maximum mid-span displacement
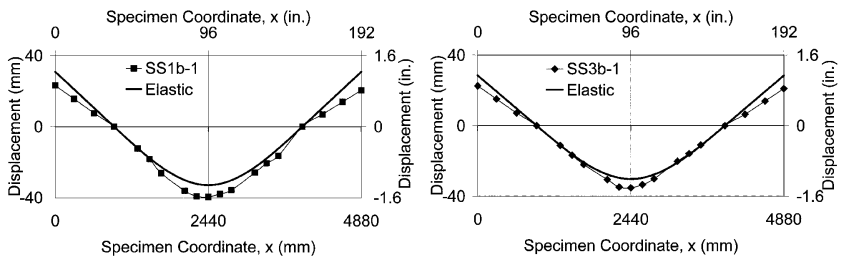

(b) Elastic shape fit into the measured slope of the specimen at the supports

Fig. 16-Elastic shape and measured displacements.

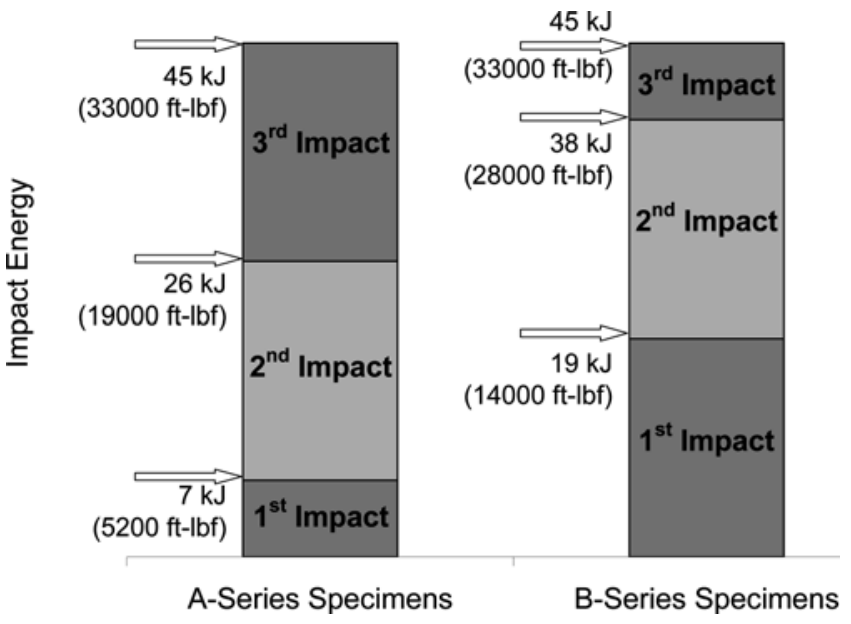

Fig. 17-Energy imparted to the specimens. considerably from the elastic shape. This deviation is more obvious in SS1b-1, for which the shear-plug was more prominent. In all specimens, the elastic shape fails to capture the deflections of the overhanging parts. This is mostly a result of the dynamic multi-degree of freedom behavior of the specimen.

\section{Impact capacities of test specimens}

The test program carried out in this study was not intended for the determination of the impact capacities of the specimens; a study with that purpose would require a significantly larger number of specimens to observe and quantify the behavioral patterns. However, some observations can still be made regarding the impact capacities based on the energy imparted to the specimens and the reaction forces recorded.

As mentioned previously, all specimens with the exception of SSOb were subjected to multiple impacts. Calculating the kinetic energy of the drop-weights with the commonly used kinetic energy formula $\left(E=1 / 2 \mathrm{mv}^{2}\right)$, the impact energy imparted to the specimens during each test can be summarized as in Fig. 17. The efforts made to determine the effect of delivering the same impact energy in varying order were mostly inconclusive. Clearly, the impact capacities of some specimens were exceeded before the third impacts. For example, SS1a experienced extensive damage after the third impact, whereas SS1b suffered approximately identical levels of damage after the second impact. Therefore, in energy terms as depicted in Fig. 17, it is safe to say that the impact energy capacity of SS1 lay somewhere between 26 and $38 \mathrm{~kJ}$. A similar conclusion can be drawn for SS0; its impact capacity was between 7 and $19 \mathrm{~kJ}$. No significant difference, however, was observed between the a-series specimens and the b-series specimens for SS3 and SS2, when their crack profiles were compared after the third impact tests. On the other hand, their crack profiles were not identical either. Because only two specimens of the same type were available for comparison, it was not possible to determine if these differences in the crack profile were insignificant, or if they were a result of a consistent behavioral difference caused by the impact chronology.

A comparison between the dynamic and static properties can be made to observe the behavioral difference between the two cases. Maximum reaction forces recorded during the impact tests are summarized in Table 3. Table 4 compares the energy imparted to the specimens with the static energy

\section{Table 3-Maximum dynamic reaction forces} recorded

\begin{tabular}{c|c|c|c|c|c}
\hline & $\begin{array}{c}\text { Maximum } \\
\text { dynamic } \\
\text { reaction } \\
\text { force, } \mathrm{kN} \\
\text { (kips) }\end{array}$ & $\begin{array}{c}\text { Ratio of maxi- } \\
\text { mum dynamic } \\
\text { reaction force to } \\
\text { maximum static } \\
\text { reaction force }\end{array}$ & Test & $\begin{array}{c}\text { Maximum } \\
\text { dynamic } \\
\text { reaction } \\
\text { force, kN } \\
\text { (kips) }\end{array}$ & $\begin{array}{c}\text { Ratio of maxi- } \\
\text { mum dynamic } \\
\text { reaction force to } \\
\text { maximum static } \\
\text { reaction force }\end{array}$ \\
\hline SS3a-1 & $431(97)$ & 2.2 & SS3b-1 & $682(153)$ & 3.4 \\
\hline SS3a-2 & $822(185)$ & 4.1 & SS3b-2 & $725(163)$ & 3.6 \\
\hline SS3a-3 & $783(176)$ & 3.9 & SS3b-3 & $613(138)$ & 3.1 \\
\hline SS2a-1 & $327(74)$ & 1.7 & SS2b-1 & $592(133)$ & 3.1 \\
\hline SS2a-2 & $651(146)$ & 3.4 & SS2b-2 & $633(142)$ & 3.3 \\
\hline SS2a-3 & $779(175)$ & 4.0 & SS2b-3 & $589(132)$ & 3.1 \\
\hline SS1a-1 & $356(80)$ & 2.4 & SS1b-1 & $625(141)$ & 4.2 \\
\hline SS1a-2 & $517(116)$ & 3.5 & SS1b-2 & $571(128)$ & 3.8 \\
\hline SS1a-3 & $314(71)$ & 2.1 & SS0b-1 & $399(90)$ & 4.1 \\
\hline SS0a-1 & $305(69)$ & 3.1 & \multicolumn{5}{l}{} \\
\hline SS0a-2 & $190(43)$ & 1.9 & & &
\end{tabular}


dissipation capacities of the specimens. Note that the maximum static reaction forces and static energy dissipation capacities were as determined from the static tests done on companion beam specimens (that is, MS0, MS1, MS2, and MS3).

It should also be noted that, in an impact test, a part of the energy imparted to the specimen is dissipated through the damage, cracking, and permanent deformations of the specimen, whereas the remainder is absorbed and released by other means, such as kinetic energy during the vibrations. In other words, the total energy dissipated by the specimen at each impact is always somewhat less than the input impact energy. Therefore, the effect of a single impact with a $45 \mathrm{~kJ}$ energy would not be identical to three impacts with a total energy of $45 \mathrm{~kJ}$. As a result, comparing the total energy of three impacts directly to the static energy dissipation capacity of the specimens can be misleading. On the other hand, such a comparison can still provide a qualitative assessment regarding the impact capacities of the specimens. For example, it can be seen that the dynamic energy dissipation capacities of the specimens are higher than the static capacities in general. The impact energy imparted on SS1a, SS1b, SSOa, and SSOb during the first impact exceeded their static energy dissipation capacity by a large margin. Except for SSOb, however, none of the specimens suffered significant damage in the first impact. Similarly, although the total energy of $45 \mathrm{~kJ}$ imparted to the specimens is larger than the static energy capacity of SS3 and SS2, these specimens did not exhibit a total failure at the end of three impacts. In other words, due to the energy dissipated through numerous other mechanisms, such as viscous damping and material hysteresis, the dynamic energy dissipation capacities of the specimens were significantly higher than their static capacities.

A similar observation can be made for support reactions as well. As can be seen from the comparisons between the static capacities of the specimens and the maximum reactions recorded, the static capacities of the specimens were severely exceeded during the tests (see Table 3). However, in most cases, the specimens exhibited sufficient resistance against these high reaction forces. This behavior was observed in other similar studies as well. ${ }^{2}$ The sharp momentary increase in capacity, by as much as a factor of 4.0 , can be attributed to material strength enhancement due to strain rate effects in both the concrete and the reinforcement, as well as to the highly dynamic conditions and the short duration of the peak forces affecting the failure mechanisms.

\section{Apparent damping}

Damping is an important parameter for an accurate prediction of the dynamic response of RC structures. Damping mechanisms in a structure are very complex, however, and currently there exists no practical way to calculate the damping analytically. On the other hand, some techniques do exist to measure the apparent damping in a structure. One of these techniques is to determine the damping by measuring the free vibration response of the structure. A damped free vibration response decays in time with an envelope curve given by Eq. (4)

$$
y(t)=\rho e^{-\xi \omega_{n} t}
$$

where $\rho$ is the displacement amplitude, $\xi$ is the damping ratio, $\omega_{n}$ is the natural angular frequency, and $t$ is the elapsed time. Free vibration can be induced with the hit of a hammer, and the resulting response can be fitted into the exponential envelope to determine its decay rate and apparent damping ratio.

During the test program, several attempts were made to induce free vibrations in a beam specimen by striking it with a rubber hammer at the midspan. In most cases, because of the significant size and stiffness of the specimens, it was not possible to induce sufficiently high displacements that could reliably be measured with the available displacement sensors. During the testing of SS1b, however, attempts to get a free vibration response were successful. Although still very small, some measurable free vibration displacements were obtained before and after test SS1b-1, which are presented in Fig. 18 for the midspan displacements. The peak points of the responses were fitted with exponential curves, also shown

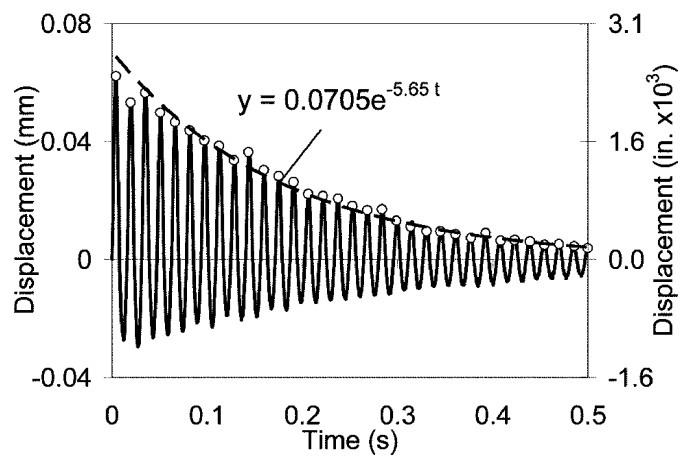

(a) before SS1b-1 test

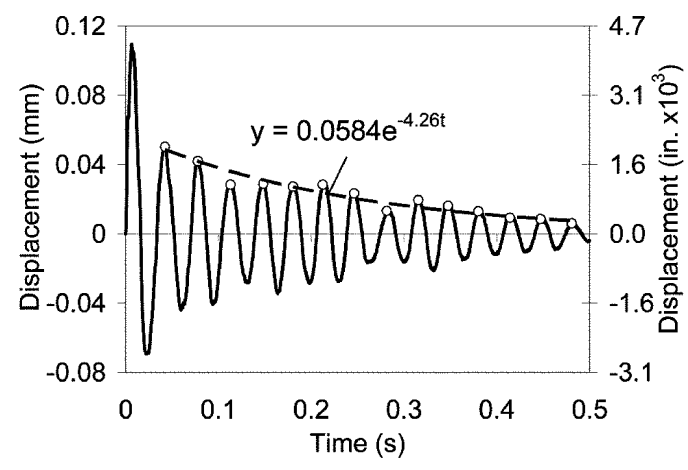

(b) after SS1b-1test

Fig. 18-Free vibrations of SS1b, midspan displacements.

Table 4-Energy imparted on specimens

\begin{tabular}{c|c|c|c|c|c}
\hline Test & $\begin{array}{c}\text { Total } \\
\text { energy } \\
\text { imparted, } \\
\mathrm{kJ}(\mathrm{ft}-1 \mathrm{bf})\end{array}$ & $\begin{array}{c}\text { Ratio of total } \\
\text { energy imparted } \\
\text { to static energy } \\
\text { dissipation } \\
\text { capacity }\end{array}$ & Test & $\begin{array}{c}\text { Total } \\
\text { energy } \\
\text { imparted, } \\
\text { kJ (ft-lbf) }\end{array}$ & $\begin{array}{c}\text { Ratio of total } \\
\text { energy imparted } \\
\text { to static energy } \\
\text { dissipation } \\
\text { capacity }\end{array}$ \\
\hline SS3a-1 & $7(5200)$ & 0.3 & SS3b-1 & $19(14,000)$ & 0.7 \\
\hline SS3a-2 & $26(19,000)$ & 0.9 & SS3b-2 & $38(28,000)$ & 1.4 \\
\hline SS3a-3 & $45(33,000)$ & 1.6 & SS3b-3 & $45(33,000)$ & 1.6 \\
\hline SS2a-1 & $7(5200)$ & 0.3 & SS2b-1 & $19(14,000)$ & 0.7 \\
\hline SS2a-2 & $26(19,000)$ & 0.9 & SS2b-2 & $38(28,000)$ & 1.4 \\
\hline SS2a-3 & $45(33,000)$ & 1.6 & SS2b-3 & $45(33,000)$ & 1.6 \\
\hline SS1a-1 & $7(5200)$ & 2.3 & SS1b-1 & $19(14,000)$ & 6.3 \\
\hline SS1a-2 & $26(19,000)$ & 8.7 & SS1b-2 & $38(28,000)$ & 12.3 \\
\hline SS1a-3 & $45(33,000)$ & 15.0 & SS0b-1 & $19(14,000)$ & 21.1 \\
\hline SS0a-1 & $7(5200)$ & 7.8 & & & \\
\hline SS0a-2 & $26(19,000)$ & 28.9 & &
\end{tabular}


in the respective figures. Accordingly, the apparent period of vibration $T$ was calculated as 0.0155 seconds prior to the test and 0.0337 seconds after the test, corresponding to angular natural frequencies of $406 \mathrm{rad} / \mathrm{second}$ and $186 \mathrm{rad} / \mathrm{second}$, respectively. By using Eq. (4) and the equations of the fitted exponential curves, the apparent damping ratios before and after the test were calculated as $1.4 \%$ and $2.3 \%$, respectively. As expected, damping increased as the specimen experienced some damage. It should be noted that the damping experienced by the structures tend to increase with the increasing displacement amplitudes. For example, similar analyses carried on the vibration response of the test SS1b-1 showed significantly higher damping ratios, reaching up to $7 \%$.

\section{CONCLUSIONS}

The test program carried out in this study was successful in providing a substantial amount of high-quality impact test data. Observations made during the tests and examination of the data collected led to the following conclusions:

1. The shear characteristics of the specimens played an important role in their overall behavior. All specimens, regardless of their shear capacity, developed severe diagonal shear cracks, forming a shear-plug under the impact point. Specimens with higher shear capacity were able to sustain more impacts and absorb more energy, whereas the ones with lower shear capacity suffered extensive damage under the same or smaller impact loads. Thus, methods developed to predict the response of reinforced concrete under impact loads must consider shear mechanisms for accurate modeling. In other words, even if the member is flexure-critical under static load conditions, ignoring shear mechanisms with methods that assume flexural behavior can lead to significant errors in the computed dynamic responses;

2. Comparisons of the measured displaced shapes with the static elastic deflected shapes revealed severe discrepancies. Therefore, simplified single degree of freedom methods, developed for impact analysis and employing elastic displaced shapes to derive the deformation characteristics of a structure, should be used with caution, especially for structures with little or no shear reinforcement; and
3. Because of the highly dynamic nature of the responses, impact forces at the initial stages of response were mainly resisted by the inertia of the specimens, before the forces reached the supports. Therefore, the mass and geometric properties of a structure, such as the span length of a beam, are important factors in resisting the impact forces. In other words, it is not possible to estimate the impact capacity of a beam accurately based only on its cross-sectional properties.

\section{ACKNOWLEDGMENTS}

The static tests reported herein were carried out by University of Toronto undergraduate students M. Egberts and A. Kong, as a part of their thesis projects. The authors would like to express their gratitude for their contributions to this study.

\section{REFERENCES}

1. Feldman, A.; Keenan, W. A.; and Siess, C. P., "Investigation of Resistance and Behavior of Reinforced Concrete Members Subjected to Dynamic Loading, Part III," Technical Report, DASA-1259, The Office of the Chief of Engineers Department of the Army, University of Illinois-UrbanaChampaign, Urbana, IL, 1962, 354 pp.

2. Kishi, N.; Mikami, H.; Matsuoka, K. G.; and Ando, T., "Impact Behavior of Shear-Failure-Type RC Beams without Shear Rebar," International Journal of Impact Engineering, V. 27, 2002, pp. 955-968.

3. Kishi, N.; Ohno, T.; Konno, H.; and Bhatti, A. Q., "Dynamic Response Analysis for a Large-Scale RC Girder under a Falling-Weight Impact Loading," Proceedings of an International Conference on Advances in Engineering Structures, Mechanics \& Construction, Waterloo, Canada, 2006, pp. 99-109.

4. Ho, D., "Impact Response of Reinforced Concrete: An Experimental and Numerical Investigation," MASc thesis, Department of Civil Engineering, University of Toronto, Toronto, ON, Canada, 2004, 267 pp.

5. May, I. M.; Chen, Y.; Roger, D.; Owen, J.; Feng, Y. T.; and Bere, A. T., "Behaviour of Reinforced Concrete Beams and Slabs under Drop-Weight Impact Loads," 6th Asia-Pacific Conference on Shock and Impact Loads on Structures, Perth, W. Australia, 2005, pp. 375-382.

6. University of Toronto-VecTor Analysis Group, http:// www.civ.utoronto.ca/vector.

7. Saatci, S., "Behaviour and Modelling of Reinforced Concrete Structures Subjected to Impact Loading," PhD thesis, Department of Civil Engineering, University of Toronto, Toronto, ON, Canada, 2007. 288 pp.

8. Comité Euro-International du Béton, "Concrete Structures under Impact and Impulsive Loading," Bulletin D'Information, No. 187, 1988, $184 \mathrm{pp}$. 
Reproduced with permission of the copyright owner. Further reproduction prohibited without permission. 